\title{
Leukemia Inhibitory Factor Extends the Lifespan of Injured Photoreceptors In Vivo
}

\author{
Sandrine Joly, Christina Lange, Markus Thiersch, Marijana Samardzija, and Christian Grimm \\ Laboratory for Retinal Cell Biology, Department of Ophthalmology, Center for Integrative Human Physiology and Neuroscience Center Zurich, University of \\ Zurich, 8091 Zurich, Switzerland
}

\begin{abstract}
Survival and death of photoreceptors in degenerative diseases of the retina is controlled by a multitude of genes and endogenous factors. Some genes may be involved in the degenerative process itself whereas others may be part of an endogenous defense system. We show in two models of retinal degeneration that photoreceptor death strongly induces expression of leukemia inhibitory factor (LIF) in a subset of Muller glia cells in the inner nuclear layer of the retina. LIF expression is essential to induce an extensive intraretinal signaling system which includes Muller cells and photoreceptors and is characterized by an upregulation of Edn2, STAT3, FGF2 and GFAP. In the absence of LIF, Muller cells remain quiescent, the signaling system is not activated and retinal degeneration is strongly accelerated. Intravitreal application of recombinant LIF induces the full molecular pathway including the activation of Muller cells in wild-type and $\mathrm{Lif}^{-/-}$mice. Interruption of the signaling cascade by an Edn2 receptor antagonist increases whereas activation of the receptor decreases photoreceptor cell death. Thus, LIF is essential and sufficient to activate an extensive molecular defense response to photoreceptor injury. Our data establish LIF as a Muller cell derived neuronal survival factor which controls an intrinsic protective mechanism that includes Edn2 signaling to support photoreceptor cell survival and to preserve vision in the injured retina.
\end{abstract}

Key words: leukemia inhibitory factor; Edn2; retina; photoreceptor degeneration; neuroprotection; endogenous rescue pathway

\section{Introduction}

Human vision depends on the absorption of photons by rod and cone photoreceptors which convert the light information into a signal which is transported by connecting neurons to the brain. This highly specialized process requires sophisticated molecular interactions between a variety of intra- and intercellular retinal components. Thus, the retina has to maintain a high integrity of its cellular architecture and of the molecular machinery of visual cells. Mutations and/or exogenous stimuli disturb the retinal integrity and may lead to photoreceptor apoptosis and retinal degeneration (Remé et al., 1998). Cells of the retina can react to unfavorable (stress) conditions or to injury with the production of various cytokines and growth factors in an attempt to protect neurons and to preserve retinal function. This might best be seen in experimental paradigms of preconditioning in which a subtoxic stimulus induces the differential expression of specific genes. This increases the resistance of the tissue to a subsequent stronger stress and thus promotes cell survival (Kamphuis et al., 2007; Zhu et al., 2007; Thiersch et al., 2008). Ischemic or hypoxic

Received 0ct. 23, 2008; revised 0ct. 31, 2008; accepted Nov. 1, 2008.

This work was supported by the Swiss National Science Foundation (Grant 3100A0-117760), a grant from the European Community (EVI-GenoRet; LSHG-CT-512036), the Fritz Tobler Foundation, the Vontobel Foundation, and the H. Messerli Foundation. We thank Coni Imsand, Hedwig Wariwoda, and Philipp Huber for excellent technical assistance and Muna Naash (VPP), Bettina Holtmann, and Michael Sendtner ( Lif $\left.^{-/-}\right)$for providing transgenic mouse lines.

Correspondence should be addressed to Christian Grimm, Laboratory for Retinal Cell Biology, Department of Ophthalmology, University of Zurich, Frauenklinikstrasse 24, 8091 Zurich, Switzerland. E-mail: cgrimm@opht.uzh.ch.

DOI:10.1523/JNEUROSCI.5114-08.2008

Copyright $\odot 2008$ Society for Neuroscience $\quad$ 0270-6474/08/2813765-10\$15.00/0 exposure are classical preconditioning schemes but light exposure below damaging threshold has also been successfully applied (O'Driscoll et al., 2008) demonstrating the existence of several activatable survival pathways in the retina.

Exposure to high levels of white light induces photoreceptor degeneration (Remé et al., 1998) and activates a signaling cascade which includes leukemia inhibitory factor (LIF), Janus kinase 2 (Jak2), signal transducer and activator of transcription 1 (STAT1) and STAT3 (Samardzija et al., 2006a). A similar retinal response has been observed in models of inherited retinal degeneration (Samardzija et al., 2006a). Since recombinant LIF can protect photoreceptor cells against light-induced degeneration (Ueki et al., 2008), the increased expression of endogenous LIF in response to damaging light suggests that LIF might be part of a retinal defense mechanism to increase survival of visual cells. Such an endogenous protective response has recently been postulated by Rattner and Nathans. In their study, they propose that injured photoreceptors produce endothelin 2 (Edn2) which signals onto Muller cells. Activated Muller cells and/or other cells may then produce and release fibroblast growth factor 2 (FGF2) to support survival of viable photoreceptors (Rattner and Nathans, 2005).

Here we focused on the role of LIF in the degenerating retina of the VPP mouse, a model for autosomal dominant retinitis pigmentosa (Naash et al., 1993; Grimm et al., 2004). We show that lack of LIF prevents Edn2 expression, STAT3 phosphorylation, FGF2 production and activation of Muller glia cells and strongly accelerates retinal degeneration. This suggests that LIF is the key factor regulating an endogenous defense mechanism to ensure survival and function of retinal cells. Since LIF expression 
Table 1. Primers used for genotyping and real-time PCR

\begin{tabular}{|c|c|c|}
\hline Gene/allele & Forward & Reverse \\
\hline \multicolumn{3}{|l|}{ Genotyping } \\
\hline VPP & AGACTGACATGGGGAGGAATTCCCAGA & CAGCTGCTCGAAGTGACTCCGACC \\
\hline Lif/wt & AAATGCCACCTGTGCCATACGC & САACTTGGTCTTCTCTGTCCCG \\
\hline Lif/KO & СTCTAAGCCTGAACTCTCTCATCC & GATTCGCAGCGCAGCGCATCGCCTT \\
\hline $\mathrm{Ccl}-2 / \mathrm{wt}$ & GGAGCATCCACGTGTTGGC & ACAGCTTCTTTGGGACACC \\
\hline $\mathrm{CCl}-2 / \mathrm{KO}$ & CTTGGGTGGAGAGGCTATTC & AGGTGAGATGACAGGAGATC \\
\hline Rd1 & CATCCCACCTGAGCTCACAGAAAG & GCCTACAACAGAGGAGCTTCTAGC \\
\hline $\mathrm{Nr} / \mathrm{wt}$ & GTGTTCCTTGGCTGGAAAGA & CTGTTCACTGTGGGCTTTCA \\
\hline $\mathrm{Nr} / \mathrm{KO}$ & TGAATACAGGGACGACACCA & GTTCTAATTCCATCAGAAGCTGAC \\
\hline \multicolumn{3}{|c|}{ Real-time PCR } \\
\hline Edn1 & TCCCGTGATCTTCTCTCTGC & AGTTCGGCTCCCAAGACAG \\
\hline Edn2 & AGACCTCCTCCGAAAGCTG & CTGGCTGTAGCTGGCAAAG \\
\hline Ednrb & ACCTACAAGTTGCTCGCAGAGG & AAAACCTATGGCTTCGGGGAC \\
\hline Smad1 & TGGTTCCAAGCAGAAGGAGGTC & GCTCATTTTGTCCCAGGTTGC \\
\hline Gfap & CCACCAAACTGGCTGATGTCTAC & TTCTCTCCAAATCCACACGAGC \\
\hline Mcl1 & GTGACTCTTATTTCTTTCGGTGCC & CATCCCAGCCTCTTTGTTTGAC \\
\hline Casp-1 & GGCAGGAATTCTGGAGCTTCAA & GTCAGTCCTGGAAATGTGCC \\
\hline Fgf2 & TGTGTCTATCAAGGGAGTGTGTGC & ACCAACTGGAGTATTTCCGTGACCG \\
\hline Cntf & CTCTGTAGCCGCTCTATCTG & GGTACACCATCCACTGAGTC \\
\hline Bdnf & CAAAGCCACAATGTTCCACCAG & GATGTCGTCGTCAGACCTCTCG \\
\hline Gdnf & AGATGAAGTTATGGGATGTCGTGG & GGCATATTGGAGTCACTGGTCAG \\
\hline$B C l-2$ & TTGTGGCCTTCTTTGAGTTCG & ATTTCTACTGCTTTAGTGAACC \\
\hline Survivin & AACTACCGCATCGCCACCTTCAAG & AGCCAGGGGAGTGCTTTCTATG \\
\hline Jak1 & TGAGCTTTGATCGGATCCTT & GCAGGGTCCCAGAATAGATATG \\
\hline Jak2 & GAACCTACAGATACGGAGTGTCC & САAAATCATGCCGCCACT \\
\hline Jak3 & CACAGTGCATGGCCTATGAT & AGGTGTGGGGTCTGAGAGG \\
\hline Tyk2 & CCTGTGTCACCTTGCTCTCA & GGAATGAGGGATGCAGTTCT \\
\hline Socs3 & GGAGACAGATGAGGCTGGTGA & GGACCTACTGACCGAGAGAT \\
\hline Stat3 & CAAAACCCTCAAGAGCCAAGG & TCACTCACAATGCTTCTCCGC \\
\hline Lif- $R$ & ACTGAAGTGGAACGACAGAGG & CTTTACCACTCAGCATTGTGTTG \\
\hline Gnat1 & GAGGATGCTGAGAAGGATGC & TGAATGTTGAGCGTGGTCAT \\
\hline Lif & AATGCCACCTGTGCCATACG & САACTTGGTCTTCTCTGTCCCG \\
\hline Mcp-1 & GGCTCAGCCAGATGCAGTTA & CTGCTGCTGGTGATCCTCTT \\
\hline
\end{tabular}

Primers for Gnat 1 were from Znoiko et al. (2005).

is specifically induced in a subset of Muller glia cells, Muller cells may coordinate the molecular response to injury and initiate an elaborate and LIF-dependent crosstalk between various retinal cells of the INL and ONL.

\section{Materials and Methods}

Mice, light exposure, intravitreal injections, and detection of cell death. Animals were treated in accordance with the regulations of the Veterinary Authority of Zurich and with the statement of "The Association for Research in Vision and Ophthalmology" for the use of animals in research. VPP mice [generous gift from Muna Naash (Naash et al., 1993)] were on a mixed SV129BL/6 background. Lif $^{-1-}$ mice (Escary et al., 1993) were kindly provided by Bettina Holtmann and Michael Sendtner (University of Wuerzburg, Germany). Ccl-2-/- (Jackson Laboratory), BALB/c mice (Harlan) and 129S6/SvEvTac (Taconic) were purchased from commercial suppliers. All mice except BALB/c and 129S6/SvEvTac (both

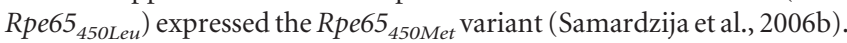
Double mutant mice were generated by classical breeding schemes. Primer pairs for genotyping are listed in Table 1. For rd1 genotyping, PCR products were digested with DdeI to detect presence or absence of the mutation as described earlier (Hafezi et al., 1998).

For light exposure, 8-week-old wild-type mice were dark-adapted overnight and their pupils were dilated with $1 \%$ Cyclogyl (Alcon) and 5\% phenylephrine (Ciba Vision) $45 \mathrm{~min}$ before exposure to 5000 lux of white fluorescent light for $2 \mathrm{~h}$. After exposure, mice were returned to darkness for $12 \mathrm{~h}$.

Intravitreal injections were performed on anesthetized animals with a $34 \mathrm{G}$ needle mounted on a $10 \mu \mathrm{l}$ Hamilton syringe. Injection site was just behind the limbus on the superior part of the eye. Intravitreal placement of the needle was observed through the pupil. One microliter of rLIF in PBS (10 ng/ $\mu$ l; Millipore), BQ-3020 in $\mathrm{H}_{2} \mathrm{O}(1 \mu \mathrm{g} / \mu \mathrm{l}$; American Pep- tide), BQ-788 in 10\%DMSO in PBS ( $2 \mu \mathrm{g} / \mu \mathrm{l}$; American Peptide) or of vehicle alone was injected within 5-10 s and the empty needle was kept in place for additional $30 \mathrm{~s}$ before it was slowly withdrawn. BQ-3020 injections were done in $129 \mathrm{~S} 6 / \mathrm{SvEvTac}$ mice $(n=21) 24 \mathrm{~h}$ before exposure to $2 \mathrm{~h}$ of 13,000 lux of white light. Analysis of cell death was $24 \mathrm{~h}$ after exposure. BQ-788 injections were done in VPP mice $(n=9)$ at PND 35 and analysis of cell death was $48 \mathrm{~h}$ thereafter. Cell death was analyzed by measuring free nucleosomes in each (total) retina individually using the cell death detection kit (Roche) according to the manufacturer's recommendations. Retinal cell death in compound injected eyes was expressed as fold-difference to cell death in the sham injected contralateral eyes of the same animal.

Microscopy and immunofluorescence. For light microscopy, eyes were fixed in $2.5 \%$ glutaraldehyde in $0.1 \mathrm{M}$ cacodylate buffer, $\mathrm{pH} 7.3$, at $4^{\circ} \mathrm{C}$ overnight. For each eye, the superior and the inferior retina were prepared, washed in cacodylate buffer, incubated in osmium tetroxide for $1 \mathrm{~h}$, dehydrated, and embedded in Epon 812. Sections $(0.5 \mu \mathrm{m})$ were prepared from the lower central retina and counterstained with methylene blue.

For immunofluorescence, mice were perfused with $4 \%$ paraformaldehyde in PBS. Eyes were removed and post fixed for $10 \mathrm{~min}$ in $4 \%$ paraformaldehyde. Cornea and lens were removed and eyecups were postfixed in $4 \%$ paraformaldehyde for additional $15 \mathrm{~min}$ at room temperature. The tissue was then incubated in 10\% sucrose (in PBS) for $10 \mathrm{~min}, 20 \%$ sucrose for $30 \mathrm{~min}$ and $30 \%$ sucrose overnight at $4^{\circ} \mathrm{C}$. Eyecups were embedded in Tissue Tec OCT (Mioles), frozen in liquid nitrogen and stored at $-70^{\circ} \mathrm{C}$ until further use. Twelve micrometer sections were cut, dried and washed in PBST (PBS $+1 \%$ Triton X-100) for $3 \times 5$ min at room temperature (RT). After blocking in PBS $+10 \%$ horse serum (HS) for $1 \mathrm{~h}$ at $\mathrm{RT}$, sections were incubated with the respective primary antibodies anti-Calbindin (AB1778), anti Brn-3a (MAB1585), anti-CHX10 (AB9014), anti-glutamine synthetase (MAB302; all Millipore), anti-Iba-1 (\#019-19741, Wako), anti-PKC $\beta$ (sc-209, Santa Cruz; kindly provided by S. Neuhauss, University of Zurich, Zurich, Switzerland), anti-Calretinin or anti-Disabled-3 (both kindly provided by E. Strettoi, Neuroscience Institute, Italian National Research Council, Pisa, Italy). Sections were washed $3 \times 10 \mathrm{~min}$ in PBS and Cy3- or Cy2conjugated secondary antibodies (Jackson ImmunoResearch) were applied in PBS $+10 \%$ HS (dilution 1:500) for $1-2 \mathrm{~h}$ at RT. Sections were washed $3 \times 10 \mathrm{~min}$ in PBS, mounted and analyzed using a Zeiss fluorescent microscope.

In situ hybridization. For in situ hybridization, nonfixed tissue was frozen in Tissue Tec OCT (Mioles). Twelve micrometer sections were cut and air dried for $20 \mathrm{~min}$ at room temperature and $10 \mathrm{~min}$ at $50^{\circ} \mathrm{C}$. Sections were post-fixed for $10 \mathrm{~min}$ at room temperature in $4 \%$ paraformaldehyde (in PBS) followed by 3 washing steps with PBS ( 5 min each). Samples were acetylated for $20 \mathrm{~min}$ at room temperature in $100 \mathrm{~mm}$ triethanolamine, $2.5 \mu \mathrm{l} / \mathrm{ml}$ acetic anhydride followed by 3 washing steps with PBS ( 5 min each). Prehybridization was done at room temperature for $2 \mathrm{~h}$ in $50 \%$ formamide, $5 \mathrm{xSSC}$, $1 \mathrm{xDenhardt}$ 's, $1 \mathrm{mg} / \mathrm{ml}$ yeast tRNA, $0.1 \%$ Tween 20, 0.1\% CHAPS, 5 mM EDTA. Hybridization was done for $16 \mathrm{~h}$ at $65^{\circ} \mathrm{C}$ in $15 \mathrm{ml}$ of the same solution including $7-15 \mu \mathrm{g}$ of DIGlabeled sense or antisense RNA probe. Slides were washed 5 times in SSC with increasing stringency and blocked in $100 \mathrm{~mm}$ Tris, $\mathrm{pH}$ 7.5, $150 \mathrm{~mm}$ $\mathrm{NaCl}$ and 1\% blocking reagent (Roche \# 1096176) for $1 \mathrm{~h}$ at room temperature. Incubation with anti-DIG antibody (Roche) in blocking buffer was for $16 \mathrm{~h}$ at $4^{\circ} \mathrm{C}$. Slides were washed twice in $100 \mathrm{~mm}$ Tris, $150 \mathrm{~mm}$ $\mathrm{NaCl}$ at room temperature for $20 \mathrm{~min}$ each, equilibrated for $5 \mathrm{~min}$ in 100 mM Tris, $\mathrm{pH}$ 9.5, $150 \mathrm{~mm} \mathrm{NaCl}, 50 \mathrm{~mm} \mathrm{MgCl}_{2}, 0.25 \mathrm{mg} / \mathrm{ml}$ levamisole (Sigma, L9756) and incubated in the same solution including $1 \mu \mathrm{l} / \mathrm{ml}$ NBT and $3.5 \mu \mathrm{l} / \mathrm{ml}$ BCIP for up to $16 \mathrm{~h}$ at room temperature. After color had developed, reaction was stopped in $10 \mathrm{~mm}$ Tris $(\mathrm{pH} 8.0) / 1 \mathrm{~mm}$ EDTA, slides were mounted and analyzed.

Combined in situ hybridization/immunofluorescence. In situ hybridization was performed as described above on perfused (4\% PFA) and cryopreserved tissue (see Microscopy and immunofluorescence) using RNase free reagents. After color development slides were washed $2 \times$ in PBS for $5 \mathrm{~min}$ each. Slides were then postfixed in 4\% PFA for $10 \mathrm{~min}$ at RT, washed $2 \times$ in PBS ( 5 min each) and the primary antibodies were applied in $5 \%$ HINGS (heat inactivated goat serum) for $3 \mathrm{~h}$ at RT. Slides were 
A

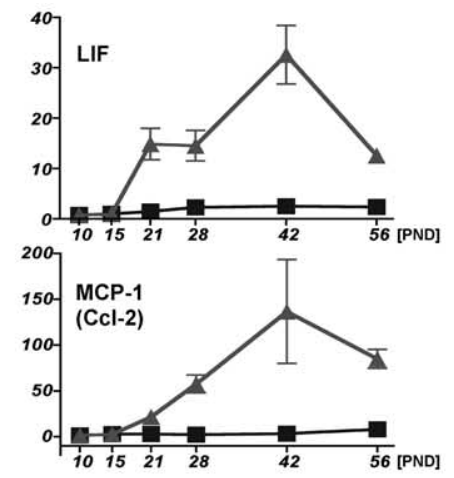

D

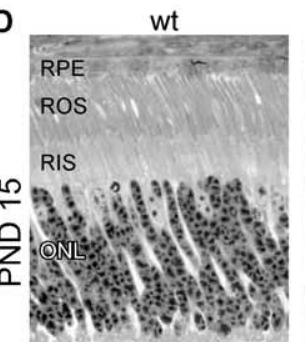

INL
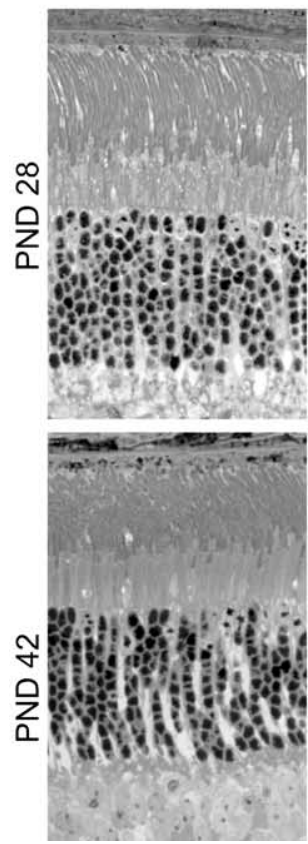

C
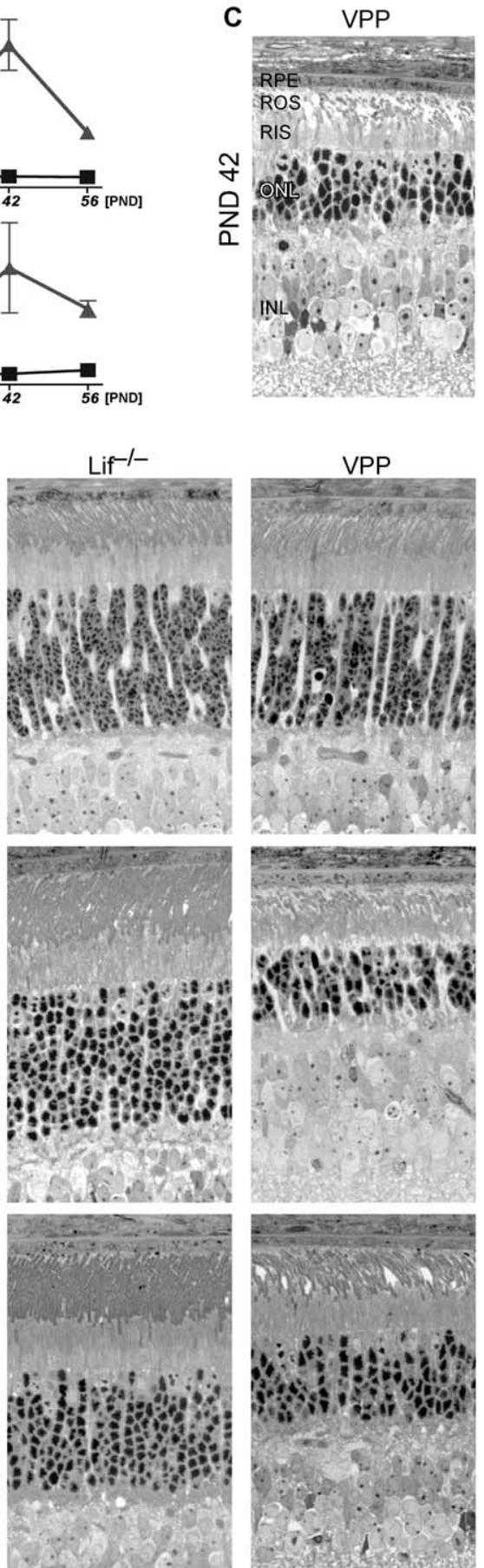
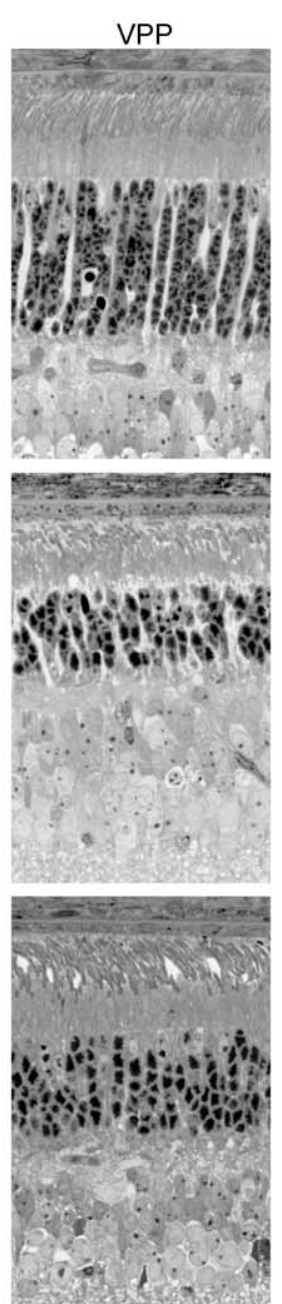
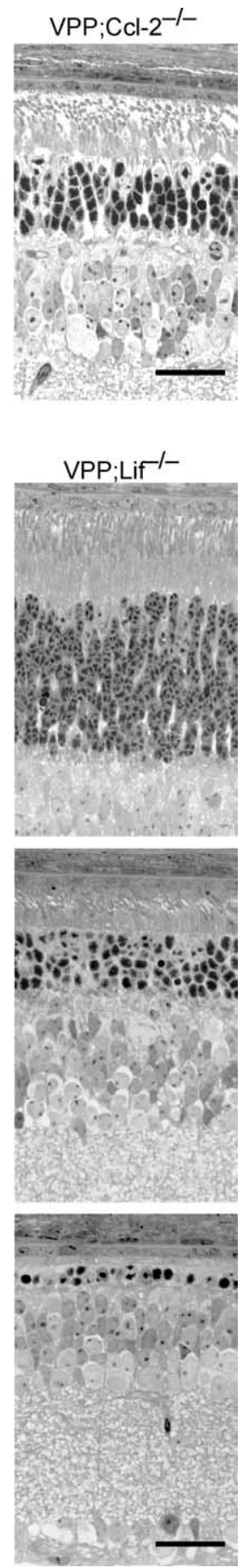

Figure 1. Lack of LIF accelerates photoreceptor degeneration in the VPP retina. $\boldsymbol{A}, \boldsymbol{B}$, Retinas from wt (squares) or VPP (triangles) mice were isolated at different postnatal days (PND) as indicated. Gene expression of LIF ( $\boldsymbol{A}$ ) and MCP-1 (CCl-2) (B) was analyzed by real-time PCR and normalized to $\beta$-actin expression. Expression of both factors was strongly induced in VPP mice starting around PND 15, concomitantly with the onset of photoreceptor degeneration. Shown are the mean mRNA levels ( \pm SD) of three independent retinas per time point and strain $(n=3)$ relative to the levels of wild-type (wt) at PND 10 which was set to 1. C, Retinal morphology of VPP (left) and VPP; $\left(\mathrm{Cl}-2^{-/-}\right.$mice (right) at PND 42. Lack of Cl-2 did not influence the degeneration as reflected by the indistinguishable retinal morphologies. Both genotypes retained $5-6$ rows of photoreceptor nuclei in the ONL compared with the $10-12$ rows in wild-type retinas (D). D, Retinal morphology of wild-type (wt), Lif ${ }^{-1-}$, VPP and VPP; Lif $^{-/-}$mice was analyzed at PND 15, PND 28 and PND 42 as indicated. Retinal morphology was similar in wt and $\mathrm{Lif}^{-/-}$at all ages tested. Retinas of VPP mice developed normally until the age of $15 \mathrm{~d}$. As expected (Samardzija et al., 2006b), many VPP photoreceptors degenerated until PND 28 before the degeneration slowed down. Photoreceptors of $\mathrm{VPP} ; \mathrm{Lif}^{-{ }^{-1}}$ mice displayed a similar degeneration until PND 28 but had a much more severe progression thereafter as seen by the single row of photoreceptors remaining at PND 42. Shown are representative panels of at least three independent retinas. RPE, Retinal pigment epithelium; ROS, rod outer segments; RIS, rod inner segments; ONL, outer nuclear layer; INL, inner nuclear layer. Scale bars, $25 \mu \mathrm{m}$.

rinsed 1 $x$ in PBS, washed 3x in PBS (5 min each) and blocked in 20\% HINGS at RT for $1 \mathrm{~h}$. The respective secondary antibodies were applied in $5 \%$ HINGS at RT for $1 \mathrm{~h}$. Slides were rinsed in PBS, washed $3 \times$ in PBS (5 min each) and mounted.

Western blotting. Retinas were homogenized by sonication in $100 \mathrm{~mm}$ Tris/ $\mathrm{HCl}, \mathrm{pH} 8.0$, and analyzed for protein content using Bradford reagent. Standard SDS-PAGE (12\%) and Western blotting of $40 \mu \mathrm{g}$ of total retinal extracts were performed. For immunodetection, the following antibodies were used: anti-STAT3 (\#9132 Cell Signaling Technology), anti-Akt (\#9272, Cell Signaling Technology), anti-gp130 (sc-656, Santa Cruz), anti-GFAP (G-3893, Sigma), anti-CRALBP (gift from John Saari, University of Washington, Seattle, WA), anti$\beta$-actin (sc-1616, Santa Cruz Biotechnology), anti-phospho-STAT3 ${ }_{\text {Tyr705 }}$ (\#9131, Cell Signaling Technology), anti-phospho-Akt ${ }_{\mathrm{Tyr} 473}$ (\#9271, Cell Signaling Technology). Blots were incubated overnight at $4^{\circ} \mathrm{C}$ with primary antibodies followed by a one hour incubation at RT with HRP-conjugated secondary antibodies. Immunoreactivity was visualized using the Western Lightning Chemiluminescence reagent (Perkin-Elmer).

RNA isolation, $C D N A$ synthesis, and real-time $P C R$. Retinas were removed through a slit in the cornea and snap frozen in liquid nitrogen. Total retinal RNA was prepared using the RNeasy RNA isolation kit (Qiagen) including a DNase treatment to digest residual genomic DNA. One microgram of total RNA were used for reverse transcription using oligo(dT) and M-MLV reverse transcriptase (Promega). cDNAs from individual animals were amplified in duplicates with respective primer pairs (Table 1) in a Light-Cycler instrument 480 (Roche Diagnostics AG) using SYBR Green I Master Mix (Roche Diagnostics AG). mRNA levels were normalized to $\beta$-actin and relative gene expression was calculated using the value of one (out of three) wild-type probe as calibrator. For statistical analysis we used ANOVA with Tukey's multiple comparison test (where more than two conditions were compared), ANOVA with Dunnett's multiple comparison test (where several conditions were compared with a control) or a one-tailed $t$ test for the comparison of the treatment in $\mathrm{Lif}^{-1-}$ animals, respectively. $\mathrm{p}$ values of $<0.05$ were considered statistically significant.

\section{Results}

Lack of LIF accelerates photoreceptor

degeneration in a model of

retinitis pigmentosa

The degenerating retina of VPP mice induces the expression of several factors connected to an inflammatory or immune response like LIF (Fig. 1A) (Samardzija et al., 2006a), monocyte chemoattractant protein-1 (MCP-1) (Fig. 1B), Casp-1, interleukin-1 $\beta$ (IL-1 $\beta$ ) (Samardzija et al., 2006c), complement component 1q $\alpha$ $(\mathrm{Clq} \alpha)$ (Rohrer et al., 2007) and comple- 

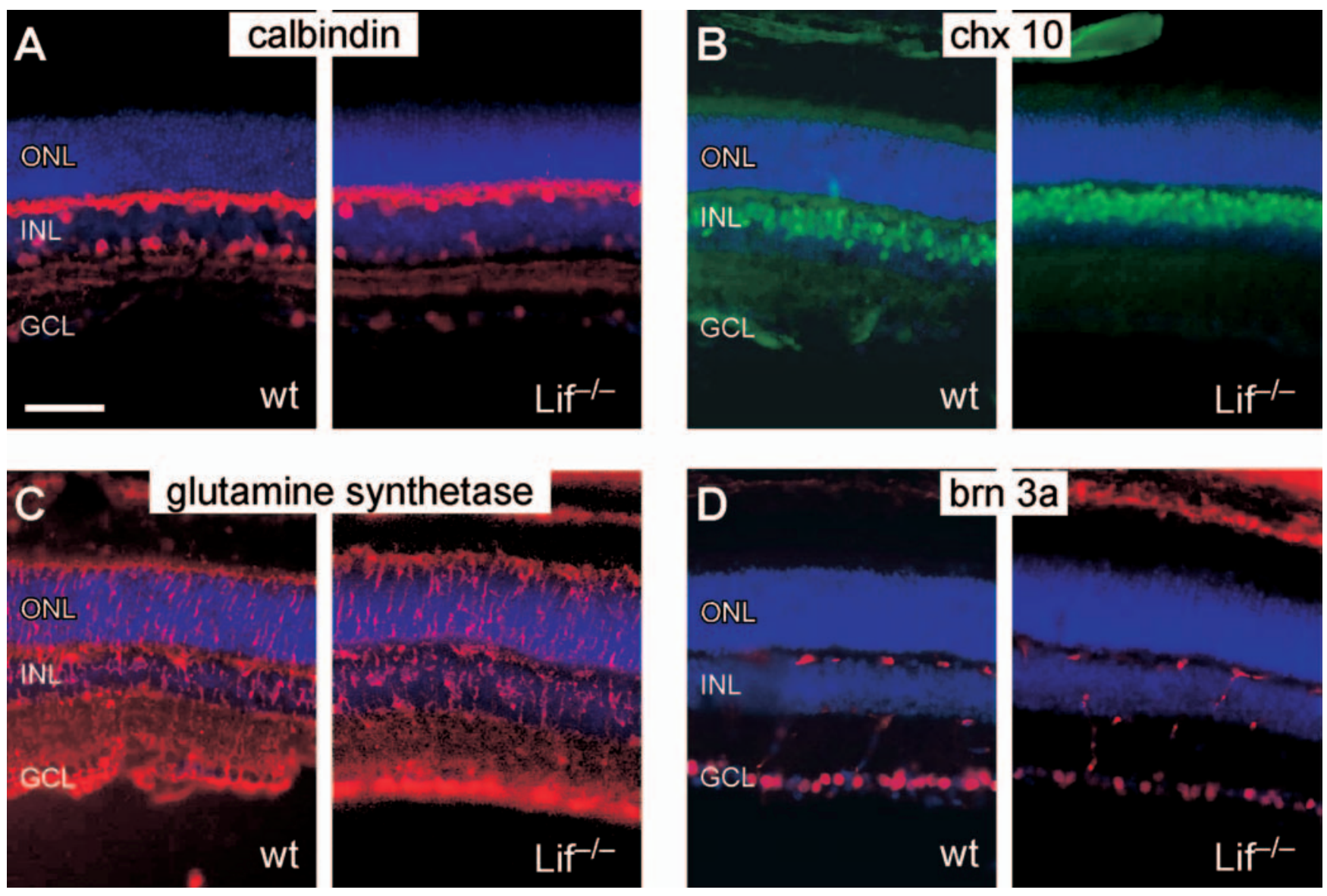

Figure 2. $\quad A-D$, Lif $^{-1-}$ retinas are similar to wild-type. Retinas of 28-day-old wild-type (wt) and Lif ${ }^{-1-}$ mice, respectively, were stained with antibodies specific for horizontal cells (calbindin, $A$ ), bipolar cells (CHX10, B), Muller glia cells (glutamine synthetase, $\boldsymbol{C}$ ) and ganglion cells (Brn3a, D). Staining patterns did not differ between wild-type and mutant retinas. GCL, Ganglion cell layer. Other abbreviations as in Figure 1. Scale bar, $50 \mu \mathrm{m}$.

ment factor $\mathrm{H}(\mathrm{CFH}$, data not shown). To analyze their potential role in the physiology or pathophysiology of the retina, we genetically inhibited MCP-1 and LIF signaling. For this purpose, we generated double mutant mice expressing the VPP transgene on a null background for either the MCP-1 chemokine $\left(\mathrm{Ccl}-2^{-/}\right)$or the LIF cytokine $\left(\right.$ Lif $\left.^{--}\right)$, respectively. Even though MCP-1 was upregulated $>100$-fold in the VPP retina, lack of functional MCP-1 did not noticeably influence the course of the disease process (Fig. 1C). In contrast, genetic ablation of LIF strongly accelerated retinal degeneration and the death of photoreceptors in VPP mice (Fig. 1D). Whereas retinas of VPP mice showed the expected slow degeneration with $\sim 6$ rows of photoreceptor cells left at PND 42, retinas of VPP mice lacking LIF showed a severely accelerated degeneration with only one row of visual cells remaining $42 \mathrm{~d}$ after birth (Fig. 1D). Onset and first phase of the degeneration was similar to VPP mice as suggested by the normal retinal appearance at PND 15 and by the only slightly reduced number of photoreceptor nuclei at PND 28.

Although LIF has been implicated in retinal development (Elliott et al., 2006) and lack of LIF was recently reported to increase microvessel density in the retina (Kubota et al., 2008), retinal morphology of Lif $^{-1-}$ mice was similar to wild-type mice at all ages tested. Retinal cell layers were well established and distribution of rods and cones was inconspicuous (Fig. $1 D$ ). In addition, immunofluorescence stainings with antibodies specific for horizontal cells (anti-calbindin), bipolar cells (anti-CHX10), Muller cells (anti-glutamine synthetase) and ganglion cells (anti-Brn3a) resulted in similar staining patterns in wild-type and knock-out mice (Fig. 2). Normal retinal architecture of $\mathrm{Lif}^{-/-}$mice is further supported by the equal numbers of retinal ganglion cells in wt and LIF knock-out animals (additional file 1). In addition, retinal function of $\mathrm{Lif}^{-1-}$ mice was comparable to wild-type animals (data not shown).

\section{Photoreceptor injury induces LIF expression in a subset of Muller glia cells}

We used in situ hybridization to localize the cells expressing LIF cytokine in response to photoreceptor injury. Whereas most cells did not show enhanced signal intensity compared with controls, few scattered cells were strongly positive for LIF expression in the INL of VPP mice at PND 28 (Fig. 3A-C). A very similar expression pattern was also found in retinas of wild-type mice at $12 \mathrm{~h}$ after exposure to damaging light (Fig. $3 D-F, G, J$ ). This suggests that the same subset of cells might be responsible for LIF upregulation in both models of retinal degeneration. Hybridization of wild-type control retinas with antisense probe did not result in such a staining pattern (Fig. $3 F$ ) demonstrating that the signal was specific for degenerating retinas. To identify the retinal cell type expressing LIF, we combined in situ hybridization with immunofluorescence using antibodies specific for individual retinal cell types. Whereas the in situ LIF signal did not colocalize with calbindin (horizontal cells), calretinin (amacrine cells), disabled-3 (type 2 amacrine cells), PKC- $\beta$ (cone bipolar cells) or Iba-1 (microglia cells) (additional file 2), it labeled a subset of 

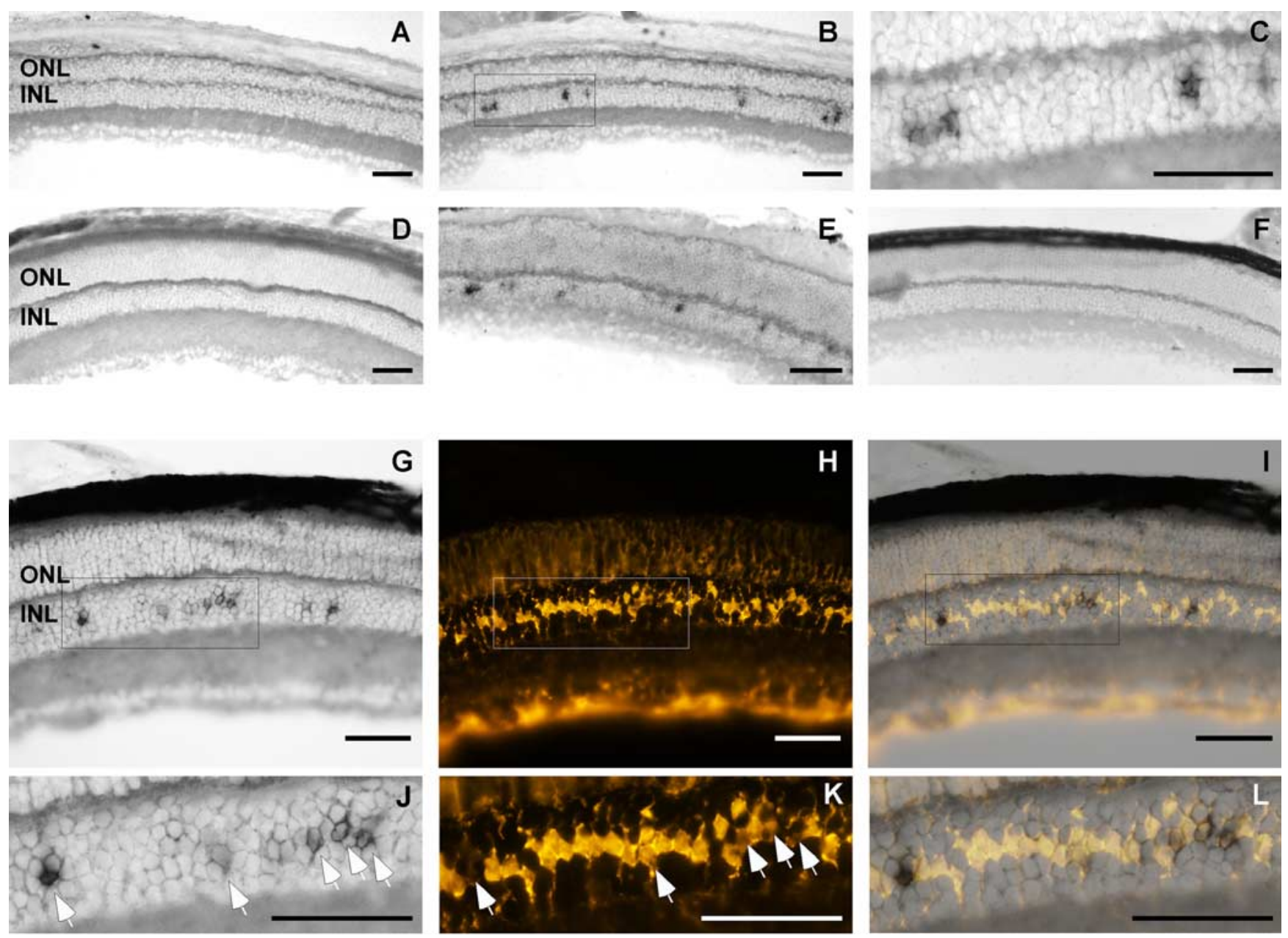

Figure 3. The degenerating retina induces LIF expression in a subset of Muller glia cells. $A-F$, In situ hybridization localizes LIF-expressing cells in the INL. Retinal sections of 28-day-old VPP mice $(\boldsymbol{A}-\boldsymbol{C})$, of wild-type $B A L B / C$ mice $12 \mathrm{~h}$ after light exposure $(\boldsymbol{D}, \boldsymbol{E})$, or of untreated wild-type mice $(\boldsymbol{F})$ were hybridized with LIF sense $(\boldsymbol{A}, \boldsymbol{D})$ or LIF antisense $(\boldsymbol{B}, \boldsymbol{C}, \boldsymbol{E}, \boldsymbol{F})$ riboprobes. $\boldsymbol{C}, \boldsymbol{H}$, igher magnification of boxed area in $\boldsymbol{B}$. LIF antisense probes specifically stained scattered cells in the INL in retinas undergoing photoreceptor degeneration $(\boldsymbol{B}, \boldsymbol{E})$ but not in a healthy retina $(\boldsymbol{F})$. $\mathbf{G}-\boldsymbol{L}$, Combined in situ and immunofluorescence stainings identified LIF-expressing cells as a subset of Muller glias. Retinal sections of wild-type $12956 / \mathrm{SvEvTac}$ mice $12 \mathrm{~h}$ after light exposure were hybridized with LIF antisense riboprobes $(\boldsymbol{G}, \boldsymbol{J})$ and anti-glutamine synthetase antibodies $(\boldsymbol{H}, \boldsymbol{K})$. The merged pictures $(\boldsymbol{I}, \boldsymbol{L})$ identified LIF-expressing cells as a subset of Muller glia cells. $J$ - $\mathbf{L}$, Higher magnifications of boxed area in $\mathbf{G}$. Arrows, cells positive for LIF and GS. Abbreviations as in Figure 1. Scale bars, $50 \mu \mathrm{m}$.

cells which stained positive for glutamine synthetase (GS) (Fig. $3 G-L)$. This clearly demonstrates that a subset of Muller glia cells upregulated LIF in response to retinal stress. It is interesting to note that the intensity of the GS staining correlated inversely with the intensity of the LIF signal (Fig. $3 \mathrm{~J}, \mathrm{~K}$ ).

\section{Lack of LIF prevents activation of Muller glia cells and blocks phosphorylation of STAT3}

Muller cell activation is one of the most common hallmarks in a degenerating retina. In virtually all cases studied, retinal Muller cells increase expression of glial fibrillary acid protein (GFAP) in response to a degenerative process (Lewis and Fisher, 2003; Bringmann et al., 2006). This has also been observed in the VPP mouse retina (Fig. 4) (Samardzija et al., 2006a). In contrast to VPP mice on a LIF wild-type background, increased expression of GFAP was completely abolished in retinas of VPP;Lif ${ }^{-1-}$ (Fig. 4). The similar expression levels of cellular retinaldehyde-binding protein (CRALBP) (Fig. 4) and the immunofluorescence staining for glutamine synthetase (GS) (Fig. 2), both Muller cell markers, show that the missing glial response was not due to a generally reduced presence of Muller cells in LIF knock-out animals.

Similarly to GFAP in Muller cells, phosphorylation of the anti- apoptotic STAT3 protein has been commonly observed during degenerative processes in the retina (Mechoulam and Pierce, 2005; Samardzija et al., 2006a; Yang et al., 2007; Ueki et al., 2008). As for the increased GFAP expression, phosphorylation of STAT3 was completely blocked in retinas of $V P P ;$ Lif $^{-1-}$ mice (Fig. 4). Since STAT3 protein was expressed at normal levels (Fig. 4) and the enzymatic machinery to phosphorylate STAT3 was intact in the $\mathrm{Lif}^{-{ }^{-}}$retina (see below), a block of upstream signaling events in the absence of LIF cytokine must account for the lack of STAT3 phosphorylation and the missing Muller cell activation in the double transgenic animals.

Akt, another kinase implicated in retinal degeneration and cell survival (Johnson et al., 2005; Jomary et al., 2006) was slightly activated in degenerating VPP retinas as evidenced by the small increase in phosphorylation observed by Western blotting (Fig. 4). Similar to STAT3, the absence of LIF prevented increased phosphorylation of Akt in response to the degeneration in the VPP; $\mathrm{Lif}^{-{ }^{-}}$retina.

\section{LIF is required for proper signaling in the stressed retina}

Recently, Rattner and Nathans (2005) identified photoreceptorderived Edn2 as a potential signaling molecule regulating a Muller glia cell response to light-mediated injury. Similar to the light- 
damaged retina (data not shown), the VPP retina strongly upregulated expression of Edn2 (Fig. 5A). Basal expression of Edn2 seemed to depend largely on LIF since Edn2 expression was reduced to $2 \%$ of wild-type levels in $\mathrm{Lif}^{-1-}$ mouse retinas. In VPP mice lacking LIF (VPP;Lif ${ }^{-1-}$ double mutants), Edn2 expression was not upregulated and remained at the low basal levels observed in the $\mathrm{Lif}^{-1-}$ retina, despite the accelerated retinal degeneration in the double mutant mice. Edn1 and Ednrb were expressed at similar levels in all mouse strains tested.

In the injured retina of the VPP mouse, GFAP was induced on the mRNA (Fig. 5B) and protein (Fig. 4) levels. Similar to Edn2, however, GFAP expression was strongly reduced in retinas of mice lacking LIF (11\% of wt) (Fig. 5B) and in contrast to VPP mice (2.7-fold elevated mRNA levels) no increased expression of GFAP was detectable in retinas of double mutant mice which is in line with our protein expression data (Fig. 4). LIF influenced also expression of Casp-1 since basal mRNA levels of this protease were reduced by a factor of 2 in retinas of Lif $^{-1}$ mice (Fig. $5 B$ ). Similar to Edn2 and GFAP, Casp-1 expression was activated in VPP retinas but not in VPP; Lif $^{-1-}$ double mutant mice. Expression of other stress related genes like Smad1 (data not shown) and Mcl1 (Fig. 5B) were not affected by the lack of LIF and/or the presence of the VPP transgene (Fig. 5B).

FGF2 is often implicated in a paracrine pathway of photoreceptor neuroprotection in various models of degeneration (Wen et al., 1995; Gao and Hollyfield, 1996; Joly et al., 2007) and is thought to be produced in an attempt to protect cells in unfavorable conditions. As such, FGF2, was also strongly upregulated in the VPP retina (10.2-fold, Fig. 5C). Strikingly, however, VPP retinas lacking LIF completely failed to induce FGF2 expression which remained at the same low basal level (38\% of wt) as observed in Lif $^{-1}$ single mutant mice ( $43 \%$ of $w t)$. Expression of other neurotrophic factors like BDNF, GDNF and CNTF remained at basal levels in the different strains with a slight upregulation of CNTF in the double transgenic retina (1.7fold induction, Fig. 5C). Similarly, expression of the anti-apoptotic genes survivin and Bcl-2, both may be regulated in a STAT3 dependent manner (Kim et al., 2006; Weerasinghe et al., 2007) remained at basal levels in the retinas of all strains tested. Thus, the lack ofFGF2 induction might have been the main reason for the accelerated photoreceptor degeneration in the VPP mouse lacking LIF.

Retinal degeneration in the VPP mouse not only induced phosphorylation of STAT3 (Fig. 4) but also STAT3 gene expression (1.9-fold) and the expression of at least two additional members of the Jak/ STAT signaling pathway (Jak3, 2.6-fold and SOCS3, 3.4-fold). Again, lack of LIF in $V P P ;$ Lif $^{-/-}$mice completely blocked activation of this signaling cascade (Fig. 5D).

In summary, all genes (Edn2, GFAP, Casp-1, FGF2, STAT3, Jak3, SOCS3) or proteins (pSTAT3, p-Akt, GFAP), which were activated in response to VPP-mediated retinal degeneration showed basal expression in the absence of LIF. This strongly suggests an essential and early role of LIF in the retinal response to photoreceptor injury.

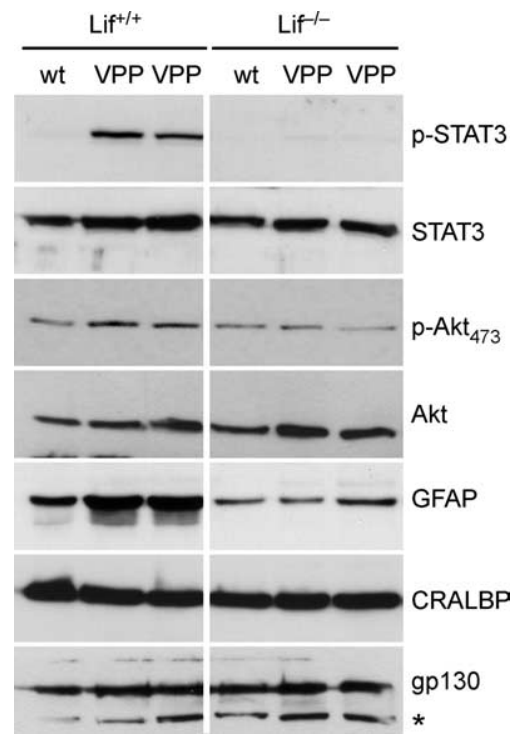

Figure 4. Lack of LIF prevents activation of STAT3, Akt and GFAP. Total retinal extracts of wt, VPP, Lif ${ }^{-/-}$and VPP; Lif ${ }^{-1-}$ retinas of 28-day-old mice were tested by Western blotting using specific antibodies as indicated. The VPP transgene on a LIF wild-type background (left) induced a strong phosphorylation of STAT3, a weak activation of Akt and a robust upregulation of GFAP. Retinas of VPP mice on a LIF knock-out background (right) did not show any signs of STAT3 phosphorylation and did not increase expression of phospho-Akt and GFP. *Nonspecific signal.
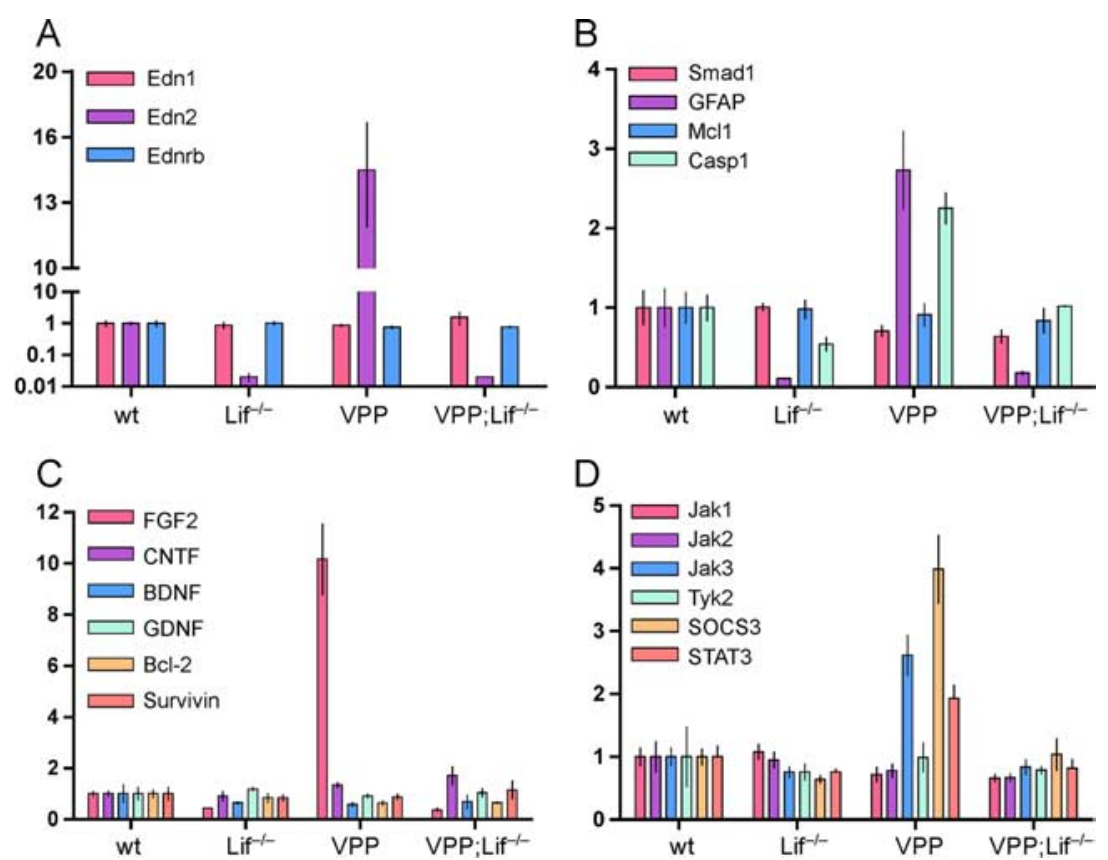

Figure 5. Lack of LIF prevents induction of a genomic response to retinal injury. Total retinal RNA was prepared from 28-dayold wt, VPP, Lif $^{-1-}$ and VPP; Lif $^{-/-}$mice. CDNA from 3 independent retinas per genotype was amplified in duplicates by real-time $P C R$. One wild-type sample served as calibrator and the mean of all wild-type samples was set to 1 for each gene amplified. Shown are means \pm SD of endothelin-related genes $(\boldsymbol{A})$, stress-related genes $(\boldsymbol{B})$, growth and survival factors $(\boldsymbol{C})$, and of genes relevant for the Jak/STAT signaling pathway (D) relative to wild-type levels. Lack of LIF caused very low basal expression levels of Edn2, GFAP and FGF2. In the presence of LIF, VPP-mediated retinal degeneration induced expression of Edn2, GFAP, Casp-1, FGF2, Jak3, SOCS3 and STAT3. The absence of LIF prevented induction of all of these genes in the VPP retina and expression levels remained at similar low levels as in $\mathrm{Lif}^{-/-}$single mutant mice.

\section{Signaling can be restored by the application of rLIF}

The missing activation of gene expression and protein phosphorylation in Lif $^{-1}$ mice could be specifically caused by the absence of LIF cytokine or by a general defect in the knock-out animals. To discriminate between these possibilities, we analyzed gene 
A

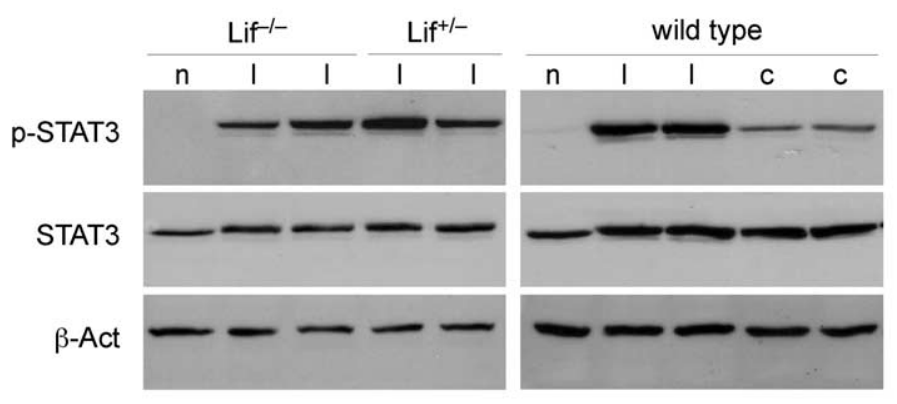

B
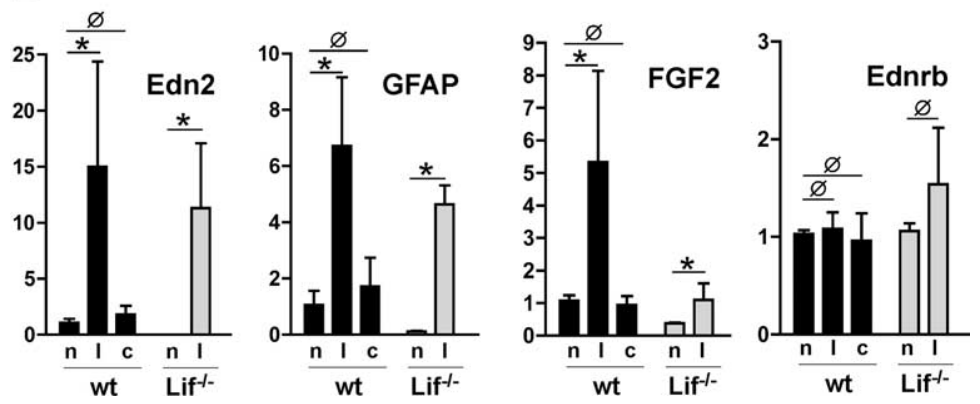

Figure 6. $\quad A, B$, Injection of rLIF restores signaling in $\mathrm{Lif}^{-/-}$mice. A total of $1 \mu \mathrm{l}(10 \mathrm{ng})$ of $\mathrm{rLIF}(\mathrm{I})$ or of vehicle control (PBS) (c) was injected intravitreally and levels of proteins or mRNAs were analyzed after $24 \mathrm{~h}$ by Western blotting $(\boldsymbol{A})$ or by real-time $P C R$ (B).A, Injection of rLIF induced phosphorylation of STAT3 in wild-type, Lif $^{+/-}$and Lif ${ }^{-/-}$mice. Control PBS injections showed only a minor response. $\boldsymbol{B}$, Gene expression of noninjected mice (n) or of mice at $24 \mathrm{~h}$ after injection of rLIF (I) or vehicle (PBS) (c) in wild-type (black bars) or Lif ${ }^{-I-}$ mice (gray bars). Shown are means \pm SD of $n=3-4$ per genotype and treatment. Levels in noninjected wild-type animals were set to $1 .{ }^{*} p<0.05 ;{ }_{p} p>0.05$. n, Noninjected; I, rLIF-injected; c, vehicle-injected.

plication (Fig. 6B). This supports our conclusion that the signaling system can efficiently be activated only in the presence of LIF. Note that the strong upregulation of LIF in wt mice may have further supported the production of Edn2 by a positive feed forward loop resulting in a signal amplification which was only possible in wildtype but not Lif $^{-1-}$ animals.

Modulation of Ednrb activation was directly relevant for photoreceptor survival. Application of the Ednrb agonist resulted in a strong tendency toward protection of photoreceptors against light damage (Fig. 7D), whereas injection of an Ednrb antagonist (BQ-788) into eyes of VPP mice significantly increased retinal cell death (Fig. $7 E)$.

\section{LIF-induced signaling and Muller cell activation may act through rod photoreceptor cells}

To investigate a potential role of photoreceptors for the signaling mechanisms induced by LIF expression, we injected rLIF into the vitreous of mice which are almost devoid of photoreceptors [3-month-old rd1 (Bowes et al., 1990)] or which have a cone-only retina $\left[\mathrm{Nrl}^{-/-}\right.$(Mears et al., 2001)]. Most importantly, although expression of genes was induced upon injections, the response did not differ between

expression after intravitreal injection of rLIF into wild-type and Lif $^{-1-}$ mice. rLIF induced phosphorylation of STAT3 similarly in all mice tested (Fig. 6A) and strongly activated gene expression of Edn2, GFAP and FGF2 in both wild-type and if $^{-1-}$ retinas (Fig. $6 \mathrm{~B})$. Although FGF2 mRNA levels in $\mathrm{Lif}^{-1-}$ retinas treated with rLIF injections did not reach levels of treated wild-type retinas, induction over nontreated retinas was nevertheless similar (5fold in wild-type and threefold in $\mathrm{Lif}^{-/-}$retinas) in the two mouse strains. It is interesting to note that rLIF induced expression of Edn2 14-fold in wild-type retinas and $>3200$-fold in $\mathrm{Lif}^{-1-}$ animals resulting in similar expression levels in the two animals after rLIF application. Control injections of carrier (PBS) resulted only in a subtle response with low levels of STAT3 phosphorylation (Fig. 6A) but not in a significant alteration of gene expression (Fig. 6B). These data show that the molecular equipment required to transduce LIF-mediated signaling was present and functional in $\mathrm{Lif}^{-/-}$retinas. This suggests that lack of gene activation was a specific consequence of the absence of LIF.

\section{Activation of Ednrb induces the molecular response and protects photoreceptors}

The receptor for Edn2 has been found to be expressed on Muller cells and potentially astrocytes in the mouse retina (Rattner and Nathans, 2005). To test whether direct stimulation of Ednrb might be able to activate the molecular response to injury we injected the Ednrb agonist BQ-3020 into the vitreous of wild-type and Lif $^{-1-}$ mice (Fig. 7). BQ-3020 efficiently induced expression of FGF2, Edn2 and LIF in wild-type retinas. In contrast, the Ednrb agonist failed to significantly induce FGF2 in if $^{-1-}$ mice and caused only a 70-fold increase of Edn2 expression in the knock-outs compared with the 3200-fold increase after rLIF ap-
rLIF and PBS-injected retinas in these two mouse strains which both lack rod photoreceptors (Fig. $8 A-F$ ), in contrast to injections into wild-type mice (Fig. $6 B$ ). This strongly suggests that a specific LIF-mediated retinal response requires rod photoreceptors.

However, it is interesting to note that basal gene expression and the response to injections differed between $\mathrm{rdl}$ and $\mathrm{Nrl}^{-1-}$ retinas in several points. (1) Basal expression of Edn2 in the aged rd1 mouse was $>1300$-fold reduced $\left(7 \times 10^{-4}\right.$ relative to wt, Fig. $8 A$ ) which is comparable to the low levels of rod specific Gnat1 (rod transducin) mRNA $\left(1 \times 10^{-4}\right.$ relative to wt) (Fig. $\left.8 F\right)$. This suggests that Edn2 is mainly expressed in photoreceptor cells. Since these cells are no longer present in rd1 mice, Edn2 expression levels are strongly reduced. Since the cone retinas of $\mathrm{Nrl}^{-/-}$ mice showed only fivefold reduced levels of Edn2 mRNA (Fig. 8 A) Edn 2 may be expressed by both rods and cones in a wild-type retina. (2) Injections ( $r L I F$ and PBS) induced expression of GFAP much stronger in the $\mathrm{rd} 1$ mouse retina than in the $\mathrm{Nrl}^{-/-}$retina (Fig. $8 B$ ). (3) Basal levels of FGF2 mRNA were higher in the $\mathrm{Nrl}^{-1-}$ retina (Fig. $8 \mathrm{C}$ ). (4) The mRNA for Ednrb was increased in rd1 (and $\mathrm{Nrl}^{-l-}$ ) retinas (Fig. 8D) compared with wild-type. This suggests that the receptor for Edn2 is expressed mainly in cells different from photoreceptors which is in line with the findings from Rattner and Nathans (2005). (5) LIF-R mRNA was reduced only sixfold in the rd1 mouse and 2.5-fold in the $\mathrm{Nrl}^{-/-}$mouse (Fig. $8 E$ ) suggesting that also cells apart from photoreceptors may express the receptor for LIF.

\section{Discussion}

Cells and tissues are equipped with endogenous protective mechanisms to cope with photoreceptor injury. Knowledge of these mech- 
anisms may allow a targeted and sustained activation of intrinsic molecular pathways which could protect cells against death in a variety of degenerative diseases. Protection against cell death may ensure functionality of the tissue which is especially important in tissues depending on quiescent post-mitotic cells like brain and retina. Here we show that the retina contains a LIF-controlled signaling system which apparently aims at the maintenance of the viability of injured photoreceptors. Activation of the system involves at least photoreceptors and Muller glia cells. The absence of LIF completely blocks this endogenous defense pathway, prevents activation of Muller glia cells in response to a stress situation and keeps several signaling and survival factors at basal expression levels. This results in a drastically accelerated degeneration of visual cells.

\section{Retinal response to injury}

Rattner and Nathans (2005) recently proposed a specific retinal response to injury which involves the production and secretion of Edn2 by injured photoreceptors leading to the activation of Muller glia cells via Ednrb and to an increased expression of FGF2. FGF2 is a potent neurotrophic factor that is upregulated in various situations of retinal stress (Gao and Hollyfield, 1996; Hackett et al., 1997; Grimm et al., 2002) and that can protect retinal cells against various insults (Unoki and LaVail, 1994; Liu et al., 1998; Yamada et al., 2001; Schuettauf et al., 2004; O'Driscoll et al., 2007, 2008).

Intriguingly, this response seems not to be initiated by the damaged photoreceptors themselves but rather by a specific subset of Muller glia cells which react with the expression of LIF to photoreceptor injury (Fig. 3). What sets the LIF-expressing Muller cells apart from other Muller cells needs to be investigated. Our combined in situ and immunofluorescence stainings suggest that cells expressing high levels of LIF have reduced GS levels. Whether this is an artificial observation due to the staining procedure needs to be analyzed but it is interesting that GS might be down regulated in pathological situations possibly through the action of FGF2 (Kruchkova et al., 2001).

The presence of LIF is required to express Edn2 to normal levels and to induce it in the stressed retina. Since Ednrb is expressed by Muller cells (which also express LIF), Edn2 signaling may induce a positive feed forward loop resulting in an increased stimulation LIF production. This is supported by the strong stimulation of LIF expression after injection of the Ednrb agonist BQ-3020 in wild-type retinas (Fig. 7). In addition to LIF, BQ-3020 application also induced Edn2 and FGF2 expression suggesting that the full response is inducible through activation of Ednrb. Indeed, activation of Ednrb protected cells against light damage and antagonizing the receptor increased cell death in the VPP mouse (Fig. 7). This demonstrates a direct relevance of the LIF-dependent Edn2 signaling for photoreceptor survival and tissue integrity. The existence of a LIFdependent positive feed forward loop is further supported by the
B
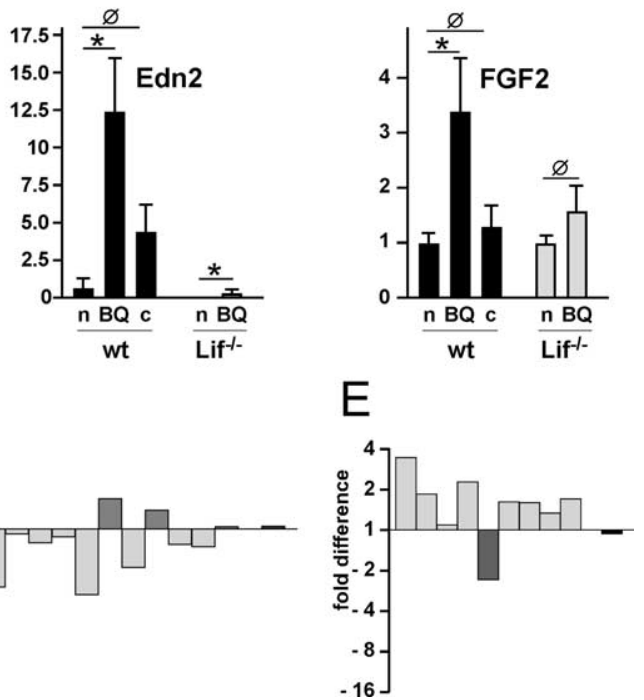

C

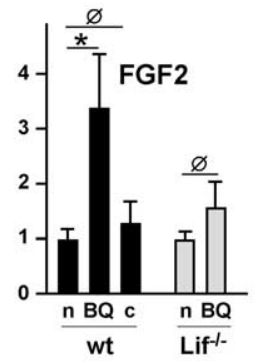

Figure 7. Modulation of Ednrb signaling influences cell survival. $A-C$, A total of $1 \mu \mathrm{l}(1 \mu \mathrm{g} / \mu \mathrm{l})$ of $\mathrm{BQ}-3020$ (BQ) or of vehicle control $\left(\mathrm{H}_{2} \mathrm{O}\right)(\mathrm{c})$ was injected intravitreally into wild-type (wt) or Lif $^{-/-}$mice as indicated. Noninjected mice $(\mathrm{n})$ served as controls.

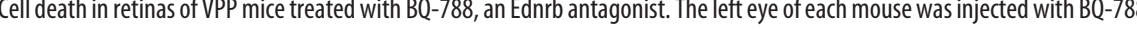
receptors after the inhibition of Ednrb signaling ( $p=0.0351$; paired Student's $t$ test). ${ }^{*} p<0.05 ;{ }^{\varnothing} p>0.05 . \mathrm{n}$, Noninjected; $\mathrm{BQ}$, BQ-3020-injected; c, vehicle-injected.

reduced molecular response in retinas of $\mathrm{Lif}^{-/-}$mice after BQ-3020 application (Fig. 7).

Since LIF-R and gp130, the two receptor subunits required for LIF binding are ubiquitously expressed in the retina including photoreceptors (Ueki et al., 2008) LIF may directly target visual cells to increase Edn2 production. This notion is supported by our observation that injection of rLIF into eyes of mice without photoreceptors (aged rd1 mice) did not provoke a similar strong response (Fig. 8).

In the presence of increased LIF, the transcription factor STAT3 is strongly phosphorylated and expression of the receptor kinase Jak3 is induced. STAT3 is a downstream mediator of gp130 signaling (Ernst and Jenkins, 2004) and is able to upregulate Jak3 expression (Mangan et al., 2004). In the absence of LIF, STAT3 protein is not activated and expression of Jak3 is not elevated suggesting that LIF may indeed signal through STAT3/ Jak3. Since lack of LIF also prevents upregulation of Edn2 expression, the regulation of these molecules may be correlated and directly or indirectly be coordinated by LIF-mediated stimulation of LIF-R.

Similarly to Edn2, STAT3, Jak3 and GFAP, induction of the survival factor FGF2 depends on LIF. It has been shown that injection of rLIF protects the retina against a toxic insult (Ueki et al., 2008), that injection of rLIF upregulates endogenous FGF2 in the retina (Fig. 6), that increased expression of endogenous FGF2 protects against retinal degeneration (O'Driscoll et al., 2008) and that lack of FGF2 activation correlates with accelerated photore- 


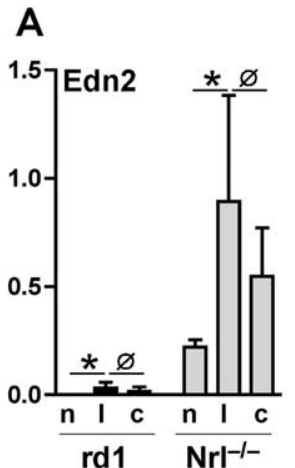

B

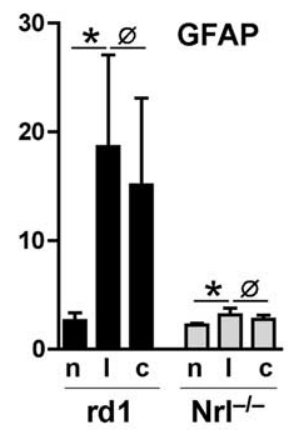

E

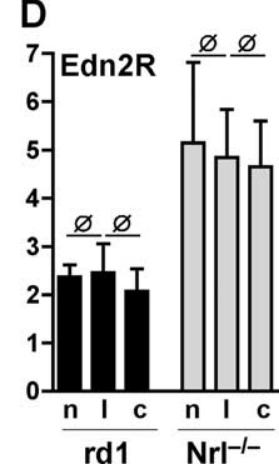

C

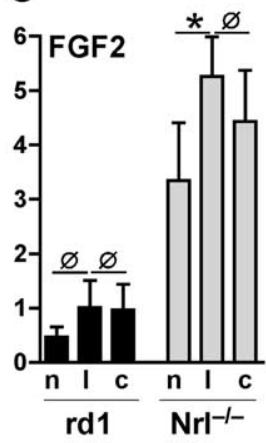

$\mathbf{F}$

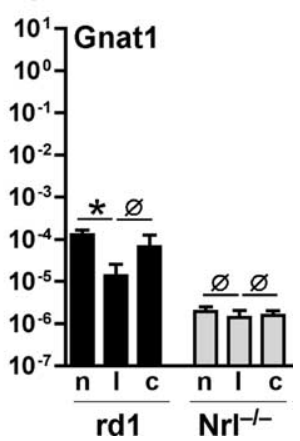

Figure 8. LIF-mediated signaling involves rod photoreceptors. One microliter (10 ng) of rLIF (I) or of vehicle control (PBS) (c) was injected intravitreally into $\mathrm{rd} 1 \mathrm{or} \mathrm{Nrl}^{-/-}$mice as indicated and relative gene expression of Edn2 (A), GFAP (B), FGF2 (C), Ednrb (D) LIF-R $(\boldsymbol{E})$, and Gnat1 $(\boldsymbol{F})$ was tested by real-time PCR on cDNA derived from total retinal RNA. Values were expressed relative to RNA levels of untreated wild-type retinas (set to 1, data not shown). Note the logarithmic scale for Gnat1. Shown are means \pm SD of $n=6(\mathrm{rd} 1)$ or $n=4\left(\mathrm{Nrl}^{-/-}\right)$per treatment. ${ }^{*} p<0.05 ;{ }^{\varnothing} p>0.05$. n, Noninjected; I, rLIF-injected; c, PBS-injected.

ceptor death (Figs. 1, 5). Thus, is seems highly likely that FGF2 is a major factor in the LIF-controlled protective mechanism. Since independent studies have reported expression of FGF2 by Muller cells (Walsh et al., 2001) and by photoreceptors (Rattner and Nathans, 2005), respectively, regulation of FGF2 expression by LIF needs further detailed investigation.

Together, our results show that LIF is not only essential but also sufficient to serve as the molecular switch to activate an endogenous protective response which may depend on the production of the survival factor FGF2.

\section{Rod photoreceptors are required for a specific LIF-mediated response}

Injection of rLIF specifically induced expression of Edn2, GFAP and FGF2 (Fig. 6). Since similar injections in the absence of rod photoreceptors did not cause a significantly different response from control injections (Fig. 8), our results suggest that rod photoreceptors play an essential and specific role in the LIF response pathway. The strong but not exclusive production of Edn 2 in rod photoreceptors is demonstrated by the 1300-fold reduced basal Edn2 levels in rd1 compared with wild-type mice. Since rd1 mice at this age ( 3 months) retain some photoreceptors, mostly cones, in the far peripheral retina (data not shown) and since the all-cone retinas of $\mathrm{Nrl}^{-/-}$mice show only fivefold reduced levels of Edn2 mRNA (Fig. 8), cones might also express Edn2 which can be stimulated by retinal injury, although not in a LIF specific way. This conclusion is supported by the lack of significant Edn2 induction in the $661 \mathrm{~W}$ cone cell line after rLIF application in vitro (data not shown).

One of the most common response to retinal injury is the upregulation of the intermediate filament protein GFAP in Muller glia cells (Sarthy and $\mathrm{Fu}, 1989$; Lewis and Fisher, 2003; Nakazawa et al., 2007). This is also evident during the degenerative process in the retina of the VPP mouse (Fig. 4). As for Edn2 and FGF2, expression and upregulation of GFAP depends on the presence of LIF (Figs. $4,5)$. The missing induction of GFAP expression in VPP; if $^{-1}$ mice suggests that photoreceptor degeneration cannot activate Muller cells and/or astrocytes in the absence of LIF. Injection of rLIF was sufficient to increase expression of GFAP (Fig. 6) but the upregulation was only specific in the presence of rod photoreceptors (Fig. 8). Thus, LIF may not directly target glial cells but may stimulate Muller cells through production of $\mathrm{Edn} 2$ in rod photoreceptors.

\section{An endogenous, LIF-mediated} neuroprotective response in the retina Based on our data and on published results (Rattner and Nathans, 2005), we suggest a model pathway which may be used by retinal cells to protect tissue integrity and to preserve photoreceptor function in the presence of damaging stress like excessive light exposure or gene mutations. We propose that a subset of Muller glia cells senses photoreceptor damage and reacts with the upregulation of LIF. Only in the presence of increased LIF, photoreceptors induce expression of Edn2 which may then signal back to Muller glia cells. This may cause a gliosis-like reaction and the stimulation of GFAP expression. Concomitantly, the survival factor FGF2 is produced in Muller cells and/or photoreceptors aiming at the protection of visual cells from further damage (additional file 3). Whether Edn2 expression occurs in healthy or already damaged photoreceptors is currently unknown. Although it was shown that Edn2 is mainly produced in the region affected by a toxic insult (Rattner and Nathans, 2005), the specific response observed after intravitreal injection of rLIF in wild-type animals suggests that also healthy photoreceptors can activate this response pathway. It is thus probable that Edn2 production is a general response of photoreceptors to increased local concentrations of LIF.

Our work establishes LIF as the key molecule in the induction of an endogenous molecular pathway aiming at the protection of photoreceptor cells in vivo. This pathway may be part of a tissue defense system which increases the survival of visual cells in situations of environmental or mutational stress. Even though the endogenous potency of the system may not be sufficient to secure the viability of the cells over an extended period of time (photoreceptors in the VPP mouse die eventually), an artificial increase of its efficacy may nevertheless offer the opportunity to significantly prolong the lifespan of visual cells in human patients.

\section{References}

Bowes C, Li T, Danciger M, Baxter LC, Applebury ML, Farber DB (1990) Retinal degeneration in the rd mouse is caused by a defect in the beta subunit of rod cGMP-phosphodiesterase. Nature 347:677-680.

Bringmann A, Pannicke T, Grosche J, Francke M, Wiedemann P, Skatchkov SN, Osborne NN, Reichenbach A (2006) Muller cells in the healthy and diseased retina. Prog Retin Eye Res 25:397-424.

Elliott J, Cayouette M, Gravel C (2006) The CNTF/LIF signaling pathway 
regulates developmental programmed cell death and differentiation of rod precursor cells in the mouse retina in vivo. Dev Biol 300:583-598.

Ernst M, Jenkins BJ (2004) Acquiring signalling specificity from the cytokine receptor gp130. Trends Genet 20:23-32.

Escary JL, Perreau J, Duménil D, Ezine S, Brûlet P (1993) Leukaemia inhibitory factor is necessary for maintenance of haematopoietic stem cells and thymocyte stimulation. Nature 363:361-364.

Gao H, Hollyfield JG (1996) Basic fibroblast growth factor: increased gene expression in inherited and light-induced photoreceptor degeneration. Exp Eye Res 62:181-189.

Grimm C, Wenzel A, Groszer M, Mayser H, Seeliger M, Samardzija M, Bauer C, Gassmann M, Remé CE (2002) HIF-1-induced erythropoietin in the hypoxic retina protects against light-induced retinal degeneration. Nat Med 8:718-724.

Grimm C, Wenzel A, Stanescu D, Samardzija M, Hotop S, Groszer M, Naash M, Gassmann M, Remé C (2004) Constitutive overexpression of human erythropoietin protects the mouse retina against induced but not inherited retinal degeneration. J Neurosci 24:5651-5658.

Hackett SF, Schoenfeld CL, Freund J, Gottsch JD, Bhargave S, Campochiaro PA (1997) Neurotrophic factors, cytokines and stress increase expression of basic fibroblast growth factor in retinal pigmented epithelial cells. Exp Eye Res 64:865-873.

Hafezi F, Abegg M, Grimm C, Wenzel A, Munz K, Stürmer J, Farber DB, Remé CE (1998) Retinal degeneration in the rd mouse in the absence of c-fos. Invest Ophthalmol Vis Sci 39:2239-2244.

Johnson LE, van Veen T, Ekström PA (2005) Differential Akt activation in the photoreceptors of normal and rd1 mice. Cell Tissue Res 320:213-222.

Joly S, Pernet V, Chemtob S, Di Polo A, Lachapelle P (2007) Neuroprotection in the juvenile rat model of light-induced retinopathy: evidence suggesting a role for FGF-2 and CNTF. Invest Ophthalmol Vis Sci 48:2311-2320.

Jomary C, Cullen J, Jones SE (2006) Inactivation of the Akt survival pathway during photoreceptor apoptosis in the retinal degeneration mouse. Invest Ophthalmol Vis Sci 47:1620-1629.

Kamphuis W, Dijk F, Bergen AA (2007) Ischemic preconditioning alters the pattern of gene expression changes in response to full retinal ischemia. Mol Vis 13:1892-1901.

Kim KW, Mutter RW, Cao C, Albert JM, Shinohara ET, Sekhar KR, Lu B (2006) Inhibition of signal transducer and activator of transcription 3 activity results in down-regulation of Survivin following irradiation. Mol Cancer Ther 5:2659-2665.

Kruchkova Y, Ben-Dror I, Herschkovitz A, David M, Yayon A, Vardimon L (2001) Basic fibroblast growth factor: a potential inhibitor of glutamine synthetase expression in injured neural tissue. J Neurochem 77:1641-1649.

Kubota Y, Hirashima M, Kishi K, Stewart CL, Suda T (2008) Leukemia inhibitory factor regulates microvessel density by modulating oxygendependent VEGF expression in mice. J Clin Invest 118:2393-2403.

Lewis GP, Fisher SK (2003) Up-regulation of glial fibrillary acidic protein in response to retinal injury: its potential role in glial remodeling and a comparison to vimentin expression. Int Rev Cytol 230:263-290.

Liu C, Peng M, Laties AM, Wen R (1998) Preconditioning with bright light evokes a protective response against light damage in the rat retina. J Neurosci 18:1337-1344.

Mangan JK, Rane SG, Kang AD, Amanullah A, Wong BC, Reddy EP (2004) Mechanisms associated with IL-6-induced up-regulation of Jak3 and its role in monocytic differentiation. Blood 103:4093-4101.

Mears AJ, Kondo M, Swain PK, Takada Y, Bush RA, Saunders TL, Sieving PA, Swaroop A (2001) Nrl is required for rod photoreceptor development. Nat Genet 29:447-452.

Mechoulam H, Pierce EA (2005) Expression and activation of STAT3 in ischemia-induced retinopathy. Invest Ophthalmol Vis Sci 46:4409-4416.

Naash M, Hollyfield JG, al-Ubaidi MR, Baehr W (1993) Simulation of human autosomal dominant retinitis pigmentosa in transgenic mice expressing a mutated murine opsin gene. Proc Natl Acad Sci U S A 90:5499-5503.

Nakazawa T, Takeda M, Lewis GP, Cho KS, Jiao J, Wilhelmsson U, Fisher SK, Pekny M, Chen DF, Miller JW (2007) Attenuated glial reactions and photoreceptor degeneration after retinal detachment in mice deficient in glial fibrillary acidic protein and vimentin. Invest Ophthalmol Vis Sci 48:2760-2768

O'Driscoll C, Wallace D, Cotter TG (2007) bFGF promotes photoreceptor cell survival in vitro by PKA-mediated inactivation of glycogen synthase kinase 3beta and CREB-dependent Bcl-2 up-regulation. J Neurochem 103:860-870

O’Driscoll C, O'Connor J, O'Brien CJ, Cotter TG (2008) Basic fibroblast growth factor-induced protection from light damage in the mouse retina in vivo. J Neurochem 105:524-536.

Rattner A, Nathans J (2005) The genomic response to retinal disease and injury: evidence for endothelin signaling from photoreceptors to glia. J Neurosci 25:4540-4549.

Remé CE, Grimm C, Hafezi F, Marti A, Wenzel A (1998) Apoptotic cell death in retinal degenerations. Prog Retin Eye Res 17:443-464.

Rohrer B, Demos C, Frigg R, Grimm C (2007) Classical complement activation and acquired immune response pathways are not essential for retinal degeneration in the rd1 mouse. Exp Eye Res 84:82-91.

Samardzija M, Wenzel A, Aufenberg S, Thiersch M, Remé C, Grimm C (2006a) Differential role of Jak-STAT signaling in retinal degenerations. FASEB J 20:2411-2413.

Samardzija M, Wenzel A, Naash M, Remé CE, Grimm C (2006b) Rpe65 as a modifier gene for inherited retinal degeneration. Eur J Neurosci 23:1028-1034.

Samardzija M, Wenzel A, Thiersch M, Frigg R, Remé C, Grimm C (2006c) Caspase-1 ablation protects photoreceptors in a model of autosomal dominant retinitis pigmentosa. Invest Ophthalmol Vis Sci 47:5181-5190.

Sarthy PV, Fu M (1989) Transcriptional activation of an intermediate filament protein gene in mice with retinal dystrophy. DNA 8:437-446.

Schuettauf F, Vorwerk C, Naskar R, Orlin A, Quinto K, Zurakowski D, Dejneka NS, Klein RL, Meyer EM, Bennett J (2004) Adeno-associated viruses containing bFGF or BDNF are neuroprotective against excitotoxicity. Curr Eye Res 29:379-386.

Thiersch M, Raffelsberger W, Frigg R, Samardzija M, Wenzel A, Poch O, Grimm C (2008) Analysis of the retinal gene expression profile after hypoxic preconditioning identifies candidate genes for neuroprotection. BMC Genomics 9:73.

Ueki Y, Wang J, Chollangi S, Ash JD (2008) STAT3 activation in photoreceptors by leukemia inhibitory factor is associated with protection from light damage. J Neurochem 105:784-796.

Unoki K, LaVail MM (1994) Protection of the rat retina from ischemic injury by brain-derived neurotrophic factor, ciliary neurotrophic factor, and basic fibroblast growth factor. Invest Ophthalmol Vis Sci 35:907-915.

Walsh N, Valter K, Stone J (2001) Cellular and subcellular patterns of expression of bFGF and CNTF in the normal and light stressed adult rat retina. Exp Eye Res 72:495-501.

Weerasinghe P, Garcia GE, Zhu Q, Yuan P, Feng L, Mao L, Jing N (2007) Inhibition of Stat 3 activation and tumor growth suppression of non-small cell lung cancer by G-quartet oligonucleotides. Int J Oncol 31:129-136.

Wen R, Song Y, Cheng T, Matthes MT, Yasumura D, LaVail MM, Steinberg RH (1995) Injury-induced upregulation of bFGF and CNTF mRNAS in the rat retina. J Neurosci 15:7377-7385.

Yamada H, Yamada E, Ando A, Esumi N, Bora N, Saikia J, Sung CH, Zack DJ, Campochiaro PA (2001) Fibroblast growth factor-2 decreases hyperoxia-induced photoreceptor cell death in mice. Am J Pathol 159:1113-1120.

Yang Z, Quigley HA, Pease ME, Yang Y, Qian J, Valenta D, Zack DJ (2007) Changes in gene expression in experimental glaucoma and optic nerve transection: the equilibrium between protective and detrimental mechanisms. Invest Ophthalmol Vis Sci 48:5539-5548.

Zhu Y, Zhang Y, Ojwang BA, Brantley MA Jr, Gidday JM (2007) Long-term tolerance to retinal ischemia by repetitive hypoxic preconditioning: role of HIF-1alpha and heme oxygenase-1. Invest Ophthalmol Vis Sci 48:1735-1743.

Znoiko SL, Rohrer B, Lu K, Lohr HR, Crouch RK, Ma JX (2005) Downregulation of cone-specific gene expression and degeneration of cone photoreceptors in the Rpe65-/- mouse at early ages. Invest Ophthalmol Vis Sci 46:1473-1479. 